\title{
Meta-heuristic optimization for a high-detail smart management of complex energy systems
}

\author{
Andrea L. Facci ${ }^{\mathrm{a}, *}$, Stefano Ubertini ${ }^{\mathrm{a}}$ \\ ${ }^{a}$ Department of Economics, Engineering, Society and Business Organization, University of Tuscia, 01100 Viterbo, Italia.
}

\begin{abstract}
Distributed generation and, in particular, cogeneration and trigeneration are generally considered viable solutions to reduce energy consumption and mitigate the environmental impact of developed economies. Nonetheless, such systems need to be carefully designed and managed to effectively meet all the economic and environmental expectations. The design of a distributed generation plant and the choice of its proper management policy are complex tasks that require effective support methodologies and tools.

In this paper, we develop a methodology to determine the optimal control strategy for a trigeneration plant. The model enforces mass end energy balances and accounts for the nonlinear and the basic dynamic behavior of each energy converter, for the time varying energy prices and environmental conditions, for maintenance and cold start costs, and for the possibility to store energy. We built on a methodology previously developed and we dramatically broaden its field of application to complex smart grids with a very high temporal detail, by cutting down its computational costs. To this aim, we implement an heuristic procedure that reduces the computational complexity of the non linear optimization problem. The total cash flow, the primary energy consumption, the plant efficiency, and the $\mathrm{CO}_{2}$ emissions, beside the instantaneous set-point of the plant, are among the most relevant results of the model.

The model is first validated through 11 test-cases specifically designed to stress the possible weaknesses of the heuristic procedure. The validation evidences that the proposed procedure does not introduce further approximations to the mathematical model. The global optimum is retrieved for all the considered cases. Afterwards, we apply the proposed methodology to a realistic energy management scenario: the assessment of a fuel cell based trigeneration plant for a civil building for a whole year. The discussion highlights the effectiveness of the proposed method for different applications including the optimization of the control strategy for existing plants, the design of new distributed generation systems, the assessment of innovative energy conversion technologies, and the evaluation of national energy policies.
\end{abstract}

Keywords: Distributed generation, CHP, Trigeneration, Smart Management, Fuel cells

\section{Introduction}

The curtailment of the energy consumption and of Green House Gas emissions (GHG) is among the most relevant issues on industrialized countries agenda [1,2].

In the last century, the worldwide Primary Energy Consumption (PEC) has constantly grown, reaching 13700 Mtoe/year in 2015, more than 2.5 times the PEC of 1971 [3, 4]. In the same time span, the $\mathrm{CO}_{2}$ emissions rose from 15500 Mton/year in 1973 to 32300 Mton in 2015. PEC and GHG emissions of nonOECD economies have sharply increased in the last decades, overwhelming the efforts of countries towards a less energy intensive development [3].

Despite the investment on energy efficiency have risen from more than 150 billion \$ per year in 2007 [5] to more than 1.7 trillion \$ per year in 2016 [6], a wider effort is required to meet the goal of keeping the global warming below $2^{\circ} \mathrm{C}$. According

\footnotetext{
*Corresponding author. Tel.: +390761357676.

Email addresses: andrea. facci@unitus.it (Andrea L. Facci), stefano.ubertini@unitus.it (Stefano Ubertini)
}

to the international energy agency (IEA) projections, following the actual energy policies the world will consume about 18000 Mtoe emitting more than $36000 \mathrm{Mt}$ of carbon dioxide by 2014 [4]. However, by the same year, PEC should be lower than 15000 Mtoe to limit the average temperature increase below $2^{\circ} \mathrm{C}$. The GHG situation is even more critical, since $\mathrm{CO}_{2}$ emissions should not exceed $18500 \mathrm{Mt} /$ year [4], about a half compared to what expected given the actual trends.

Several technological alternatives might contribute to reduce energy consumption and GHG emissions including, among many other: (i) incrementing the renewable energy penetration [7-9]; (ii) improving the buildings efficiency [10, 11]; (iii) decarbonizing the transport sector [12]; (iv) promoting distributed generation (DG) and cogeneration (CHP) or trigeneration (CHCP) [7, 9, 13-17]; (v) employing mechanical, electrical or thermal energy storage [18-24]; (vi) promoting hydrogen energy technologies and fuel cells (FC) [10, 25-28]. All these measures require large investments, significant design efforts, or might need further technological developments before industrialization and commercial diffusion (e.g. high temperature FCs). A significant increment of the renewable penetration also arise 


\section{Nomenclature}

$\begin{array}{ll}\text { CHCP } & \text { Combined Heat Cooling and Power } \\ \text { CHP } & \text { Combined Heat and Power } \\ \overline{\mathrm{COP}} & \text { Coefficient Of Performance of the heat pump } \\ C_{f} & \text { Fuel cost } \\ C_{m} & \text { Maintenance cost } \\ C_{s} & \text { Cold start ost } \\ \mathrm{DG} & \text { Distributed Generation } \\ E_{\mathrm{ch}} & \text { Total cooling energy required throughout the } \\ & \text { year } \\ E_{\mathrm{el}} & \text { Total electrical energy required throughout the } \\ E_{f} & \text { year } \\ E_{\mathrm{grid}} & \text { Fuel energy } \\ E_{\mathrm{th}} & \text { Electricity exchanged with the grid } \\ & \text { Total thermal energy required throughout the }\end{array}$

FC Fuel Cell

GHG Green House Gas Emissions

HoP Heat over power ratio

LHV Lower Heating Value

NG Natural gas

$N_{s_{t}} \quad$ Number of possible set-points for the thermal storage

PEC Primary Energy Consumption

$\mathrm{PEF}_{f} \quad$ Primary Energy Factor of the fuel

$\mathrm{PEF}_{\text {grid }}$ Primary Energy Factor of the grid

$R \quad$ Revenue/cost yielding from the electricity exchanged with the grid

UF
$\mathrm{UF}_{\text {boi }}=0$ Boiler Utilization factor

$\mathrm{UF}_{\mathrm{FC}} \quad$ Fuel cell utilization factor

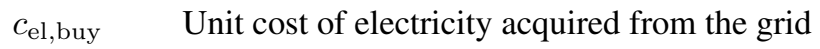

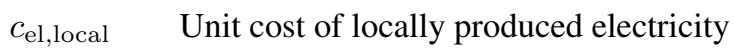

$\overline{c_{\text {el,sell }}} \quad$ Averege unit price of electricity sold to the grid

$c_{\text {el,sell }} \quad$ Unit price of electricity sold to the grid

$c_{\text {fuel }} \quad$ Unit cost of the fuel

$c_{\text {gas }} \quad$ Unit cost of natural gas

$c_{\text {on }} \quad$ Cold start cost for a single equipemnt

$h \quad$ Time interval

$i \quad$ Index of the subsystem

$n_{\psi(i)} \quad$ Number of the elements of $\psi$

$n_{s p} \quad$ Number of discrete set-points considered for each equipment

$p \quad$ Number of nodes of the graph

$q \quad$ Number of arcs of the graph

$s(h) \quad$ Plant state

$t \quad$ Time

$\mathcal{I} \quad$ Capital investment

$\Theta \quad$ Number of equivalent hours per year

$\eta_{\text {boi }} \quad$ Boiler efficiency

$\eta_{\text {eg }} \quad$ Efficiency of the electric generator

$\psi \quad$ Constrants array related to cold start costs and minimum stay constraints

$\sigma_{c_{\mathrm{el}, \mathrm{sell}}} \quad$ Standard deviation of $c_{\mathrm{el}, \mathrm{sell}}$

$\tau_{\text {off }} \quad$ Minimum stay constraint relative to the off state

$\tau_{\text {on }} \quad$ Minimum stay constraint relative to the on state concerns on the stability of the electricity distribution networks [29-32].

The optimization of existing and new power plants is also a viable option to reduce energy costs, PEC, and the GHG emissions [33-38]. In fact, the control strategy significantly impacts the real performance of any energy system [33, 34, 39-42], as the efficiency and emissions of all the machineries are functions of their set-point $[17,41,43]$. On the one hand, this means that even the most efficient energy system should be carefully managed to effectively meet all the design expectations [44]. On the other hand, updating the control strategy of existing plants could generate significant benefits with negligible capital investments [33-35, 44, 45]. Similarly, optimized management policies could boost the performance of advanced technologies facilitating their exploitation [10].

The design of a new power plant, rather than relying on rated efficiency, should leverage on the evaluation of the effective performance that is influenced by the time varying energy demand and costs, by the environmental conditions, and by the machinery derating and constraints $[10,17,34,43,45,46]$. Similarly, policy makers could simulate realistic energy management scenarios to determine the impact of each technology on national energy systems, or to assess the effectiveness of the energy policies in promoting energy efficiency and GHG reduction [39]. As a consequence, models and methodologies that a-priori determine the optimal management policy of an energy conversion plant are fundamental tools towards energy efficiency, against global warming and fossil fuel depletion. 
The control strategy optimization of a generic power plant is a complex non linear problem that requires a significant modeling and computational effort $[34,44]$. Nevertheless, linear approximations are often utilized to describe inherently non linear energy conversion processes [47-50]. Instead the Authors of [51-53] use non-linear programming, while others [46, 54] leverage on mixed integer linear programming. Stochastic optimization algorithms are also adopted for energy system dispatch [55-57] or sizing and placement [58] optimization and Lagrange multipliers are adopted in [43]. Dynamic programming is also an effective methodology for energy system optimization [10, 21, 22, 26, 35, 45, 59] that allows to account for the inherent non-linearity of energy conversion processes [35], for the basic dynamic behavior of the machineries [35], and for the possibility to store mechanical and thermal energy [22].

In this paper, we build on the methodology introduced in [35] and [22] to broaden its field of application by reducing the computational complexity. The effectiveness of such a method was demonstrated in different cases ranging from the optimization of CHCP systems [35], and heat ventilation and air conditioning plants [60], to the optimal sizing of energy storage systems [22], and the assessment of the performance of innovative conversion technologies [10]. Specifically, we introduce an heuristic model that drastically scales down the dimension (i.e. the number of nodes and arcs) of the graph that represents the optimization problem. Such an heuristic reduces the number of nodes by 6 order of magnitude for a realistic test case with respect to the baseline methodology.

The paper is organized as follows. In section 2 we thoroughly describe and validate the optimization methodology. In particular, in subsection 2.1 we focus on the heuristic, and in subsection 2.2 we validate it through 11 specifically designed test-cases. In section 3 we apply the proposed method to a realistic energy management scenario: the optimization of a CHP plant based on PEM fuel cells that serves a small Hotel in an heating based climate. The power plant is optimized for 8760 $\mathrm{h}$ following both cost and PEC minimization. Subsections 3.1 and 3.2 describe the CHP plant and the encompassing energy system, while subsection 3.3 discusses the energy demand. The results of the optimization are presented in subsection 3.4 highlighting several potential applications of the proposed methodology. Conclusions are drawn in section 4.

The analysis of the test case results demonstrate the applicability of the proposed methodology. In fact, the optimization of a whole year of a CHP plant requires about $2.5 \mathrm{~h}$ on an average quality desktop computer. Moreover, the results evidence the impact of the control strategy on the effective performance of the CHP plant: switching from cost to PEC minimization reduces the energy consumption by $13 \%$ while the increase in the energy cost is in the range $[13 \%, 33 \%]$ as a function of the plant configuration.

\section{Methodology}

\subsection{Heuristic discretization of the plant state}

Determining the optimal control strategy of a multi-generation plant is a complex task $[22,35]$. Such plants usually in- clude different subsystems: fuel boilers, electrical power generators, heat recovery boilers, mechanical and/or absorption chillers, 122 energy storage, and possibly other. The objective function and ${ }_{123}$ the constraints deriving from energy and mass balances are nonlinear, being the system efficiency a function of the set-point $[34,35,53]$. The energy storage and the costs or constraints related to turning on and off the equipments establish a mathematical connection between the time-steps [22,35]. Thus, a proper optimization procedure requires to determine the minimum of a non-linear function that depends on a huge number of variables that are the set-points of each subsystem of the plant at each time-step.

In this paper we further develop a methodology already tested ${ }_{133}$ and validated in previous works $[22,35]$ with the aim to signif- ${ }_{134}$ icantly reduce its computational cost and broaden its effective applicability.

Such a methodology utilizes a lumped parameter approach, where all the subsystems are modeled as black-boxes. The model accounts for: (i) the design performance of all the subsystems; (ii) the derating of the performance at part load; (iii) the effects of environmental conditions on the efficiency and on the maximum power of the machineries; (iv) energy demand and costs as functions of time; (v) maintenance, and cold start (ignition) costs; (vi) constraints related to the dynamic behavior of the equipment, such as the minimum time interval between two consecutive starts or shutdowns (minimum stay constraints); (vii) the possibility to store energy. Two different objective functions are considered so far. Economic optimization minimizes the total operating costs, calculated through the following equation:

$$
\begin{aligned}
G_{\text {Cost }} & =\sum_{h=1}^{N_{\text {Time }}} C_{f}(h, s(h))+C_{m}(h, s(h))+ \\
& +C_{s}(h, s(h), s(h-1))-R(h, s(h)),
\end{aligned}
$$

where $h$ is the time interval, $C_{f}$ is the cost of fuel, $C_{m}$ is the maintenance cost $C_{f}, C_{s}$ is the cold-start cost $C_{f}$, and $R$ the revenue/cost yielding from the electricity exchanged with the grid $C_{f}$. Costs are functions of the time interval and the plant state (i.e. the set-point of the subsystems) $s(h)$. Primary energy consumption is minimized thorough the following objective function:

$$
\begin{aligned}
G_{\mathrm{PEC}}= & \sum_{h=1}^{N_{\text {Time }}} E_{f}(h, s(h)) \mathrm{PEF}_{f}+ \\
& +E_{\text {grid }}(h, s(h)) \mathrm{PEF}_{\text {grid }},
\end{aligned}
$$

where $E_{f}$ is the energy content of the fuel, $\mathrm{PEF}_{f}$ is the primary energy factor of the fuel [61], $E_{\text {grid }}$ is the electricity exchanged with the grid, and $\mathrm{PEF}_{\text {grid }}$ is the primary energy factor of electricity [61]. The implementation of other objective functions, such as carbon dioxide or pollutant emissions [34], or plant efficiency is straightforward. The objective function is discretized with respect to the plant state and in time, and the problem is represented as a weighted and oriented graph as the one depicted in Figure 1. The costs that are functions of the 123 


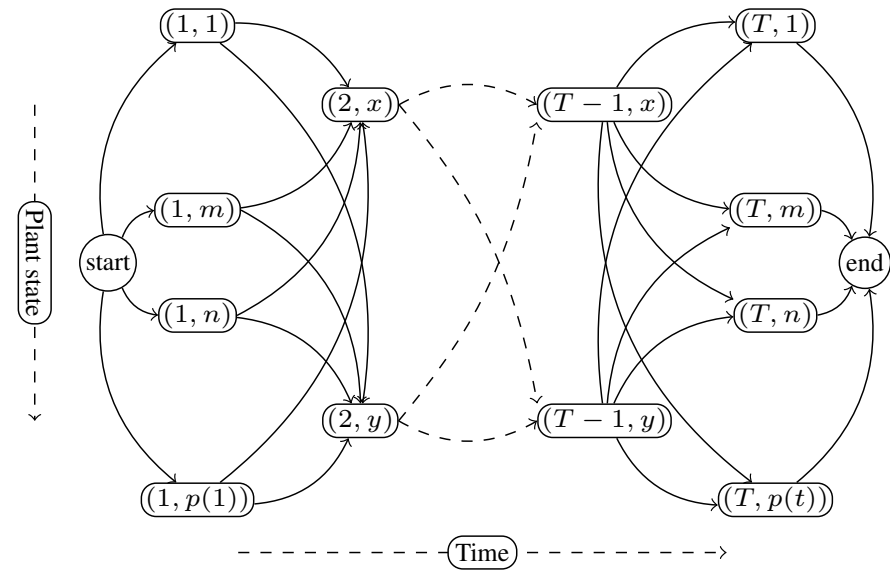

Figure 1: Schematic representation of the graph resulting from the discretization of the optimization problem.

sub-systems set-point at the local time, such as fuel costs, are associated to the graph nodes. Conversely, costs that depend on the set-point variation, such as cold-start costs, are associated to arcs. The optimal control strategy is determined by seeking for the shortest path across the graph through dynamic programming $[22,35,62,63]$.

A number of studies demonstrate the effectiveness of such a methodology $[10,22,26,45,60]$ for different applications including the techno-economic evaluation of PEM and SOFC based CHP systems [10, 26], the optimal sizing of the thermal energy storage for CHP plants [22], the evaluation different optimization criteria [45], and the optimization of heat ventilation and air conditioning plants [60]. Nevertheless, the size of the graph (i.e. the number of nodes and arcs) grows very fast with the number of subsystems $N_{\text {sys }}$ and of time-steps. This represents a severe drawback and hampers the possibility of using such a procedure for complex systems (e. g. smart cities) and for a long time-interval (e. g. one or more years of continuous operation). In fact, the number of nodes for each time-step is

$$
p=\prod_{i=1}^{N_{\mathrm{sys}}} n_{s p}(i)
$$

being $n_{s p}(i)$ the number of discrete set-points considered for each equipment, and the number of arcs is

$$
q=N_{\text {time }} p^{2} .
$$

This methodology allowed the optimization of relatively simple power plants, ( 1 to 5 subsystems) for a time-span of one day (i.e. 24 hours) $[10,22,26,35,45,60]$. The optimization of larger systems and/or with a longer time interval require a significant reduction of the computational effort.

Here we implement an heuristic procedure that drastically reduces the number of nodes of the graph. In the methodology described in [22, 35, 45] for each time-step the graph is populated by the bare combinations of all the discrete set-points of all the plant subsystems. Most of these combinations are practically useless. Either because they do not fulfill the constraints, either because they are so far from being optimal that they cannot be part any minimum path even after considering the arcs costs (i.e cold start costs) or the constraints related to cold start, nor in presence of thermal storage.

The idea underlying the proposed heuristic is that only the points that are, to some extent, optimal are retained in the graph.

We generate a constraint array $\psi$ related to cold start costs and minimum stay constraints. If the subsystem $i$ has a cold start cost $\left(c_{\mathrm{on}}>0\right)$, or if it is subject to a minimum stay constraint $\left(\tau_{\text {on }}>0\right.$ or $\left.\tau_{\text {off }}>0\right)$ it might be forced to be on or off depending on its state at the previous or following time-step. Then, the constraint can assume one of the values "on", "off", or "any": $\psi(i)=\{$ on, off, any $\}$. Conversely, if none of the previous conditions applies, $\psi(i)$ can only assume the value "any": $\psi(i)=\{$ any $\}$. The pseudocode for the determination of $\psi$ is reported in Algorithm 1.

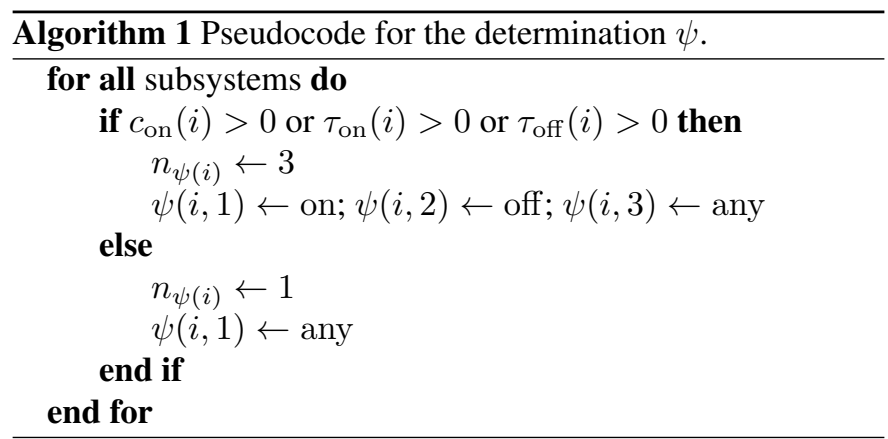

Thermal storage also establishes a mathematical connection across the different time-steps. Thermal energy produced at time $t$ might be consumed at any subsequent time-step. Thereafter, if thermal storage is preset, it is always allowed to have any of the possible set-points, or, equivalently to store or release an arbitrary amount of power. At each time-step, we populate the graph by determining the optimal set-point of all the subsystems except for the the thermal storage, for all the possible combinations of $\psi$ and of the thermal storage set point, as evidenced in Algorithm 2.



The number of nodes for each time-step is dramatically re- ${ }_{229}$ duced, being:

$$
p^{*}=N_{s_{t}} \prod_{i=1}^{N_{\mathrm{sys}}} n_{\psi(i)}
$$


begin $N_{s_{t}}$ the number of possible set-points for the thermal storage and $n_{\psi(i)}$ the number of elements of $\psi(i)$. Note that, since $\psi(i)=3$ in the worst case, $p^{*} \ll p$. The proposed heuristic significantly reduce the dimensions of the graph while retaining all the mathematical features of the problem in study. Moreover, it does not introduce any approximation with respect to the methodology described in [35].

The minimum path across the graph is determined through the algorithm described in [22, 35, 45].

The determination of the local minima and of the shortest path across the graph require the majority of the computational time. Therefore, these part of the model are implemented through the OpenMP API specification for parallel programming [64] and can be executed in parallel on shared memory computers.

\subsection{Validation}

To validate the method described in subsection 2.1 we apply it to 11 simplified cases that are specifically designed to facilitate the verification process. On one hand the optimal control strategy can be easily determined a-priori and compared to the result of the proposed algorithm. On the other hand, the energy demand, costs, and plant configurations are selected to generate difficult situations for the optimization procedure. A realistic simulation is provided in section 3 to highlight the potential of the proposed model.

For all the validation cases we consider a 24 hours time interval and we assume economic optimization. (a) Thermal demand



(b)Set-point

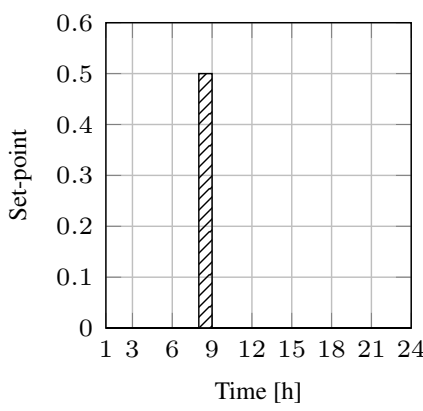

Figure 2: Representation of energy demand and set-point of the boiler as functions of time for validation case 1 .

Case 1. Energy demand has a single $50 \mathrm{~kW}$ peak of thermal load from 8 a.m. to 9 a.m. as evidenced in Figure 2(a). The plant is made of a single $100 \mathrm{~kW}$ boiler with constant efficiency and there is no thermal storage.

As expected the boiler operates at $50 \%$ power between 8 a.m. and 9 a.m. as shown in Figure 2(b).

Case 2. The thermal energy demand represented in Figure 3(a) is characterized by a 2 hours $50 \mathrm{~kW}$ peak. It is satisfied through a power plant composed of a $100 \mathrm{~kW}$ boiler and of a thermal energy storage. The efficiency of the boiler linearly increases from 0 to 1 as the power output varies from $0 \mathrm{~kW}$ to nominal power. The thermal storage has a capacity of $277 \mathrm{kWh}$ and can deliver up to $100 \mathrm{~kW}$ of heating power with a constant efficiency equal to 1 .

Figure 3(b) represents the optimal set-point of the boiler and of the thermal storage. Therein, the negative set-point is used for the thermal storage to represent the energy flux from the boiler to the storage. Conversely, positive set point for the thermal storage indicates that heat is directed from the reservoir to the energy demand. (a) Thermal demand

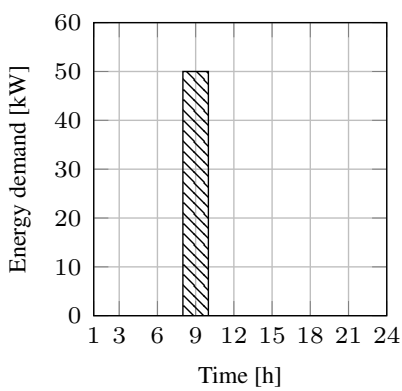

Figure 3: Representation of energy demand and set-point of the boiler and of the heat storage as functions of time for validation case 2 .

The economic optimization dictates that the the boiler is operated at full load for 1 hour to maximize its efficiency (see Figure 3(b)). At the same time $100 \mathrm{kWh}$ of heat are stored in the thermal reservoir. Heat is then released from the thermal storage (positive set-point equal to $50 \%$ ) to fulfill the energy demand.

This case evidences the ability of the proposed methodology to correctly detect the globally optimal control strategy with the presence of a thermal storage. In fact, at each timestep the plant state reported in Figure 3 does not minimize the instantaneous cost at the local time. Instead, the total cost for the whole simulation period is optimized.

Case 3. The $50 \mathrm{~kW}$ one hour peak thermal demand of Figure 4(a) is satisfied by a $100 \mathrm{~kW}$ boiler without thermal storage. The boiler has a constant efficiency and is constrained to operate for at least 3 hours after each cold start. The minimum allowed set-point is $1 \%$. (a) Thermal demand

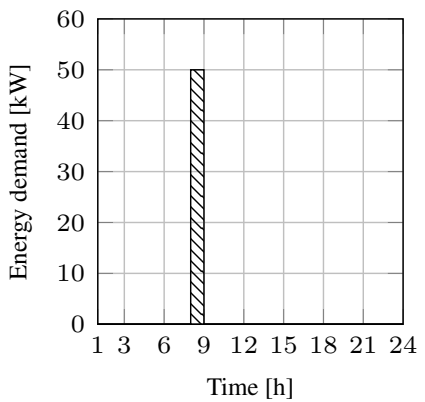

(b)Set-point



Figure 4: Representation of energy demand and set-point of the boiler as functions of time for validation case 3 . 
Figure 4(b) shows that the energy system correctly operates at $50 \%$ power from 8 a.m. to 9 a.m. to satisfy the energy demand. It remains at idle for the two adjacent hours to fulfill the minimum stay constraint while minimizing the fuel cost. Thereafter, the constraints that correlates consecutive time-steps are correctly applied. (a) Thermal demand



(b)Set-point



Figure 5: Representation of energy demand and set-point of the boiler as functions of time for validation case 4 .

Case 4. The heat demand is composed by two peaks of $50 \mathrm{~kW}$ power and 1 hour duration (from 8 a.m. to 9 a.m and from 10 a.m. to 11 a.m.) separated by 1 hour of zero energy demand (see Figure 5(a)). Such a demand is satisfied by a single 100 $\mathrm{kW}$ boiler characterized by a constant efficiency $\eta_{\text {boi }}=1$ and by a cold start cost $c_{\text {on }}=5 €$. The fuel costs $1 € / \mathrm{kg}$ and its lower heating value is $36 \mathrm{MJ} / \mathrm{kg}$. The minimum allowed setpoint is $1 \%$.

According to the optimal control strategy, reported in Figure 5, the set-point of the boiler is $50 \%$ during the peak demand hours and $1 \%$ from 9 a.m to 10 a.m.. In fact, the fuel expenditure for 1 hour at idle is $0.1 €$ and is much lower compared to the cold start cost.

This test case evidences that the treatment of the costs that are functions of the set-point at different time-steps is correct.

Case 5. Both the energy demand and the power plant are the same of case 4 except that $c_{\mathrm{on}}=0$ and for the boiler operation constraint, which is now $\tau_{\text {off }}=3 \mathrm{~h}$.

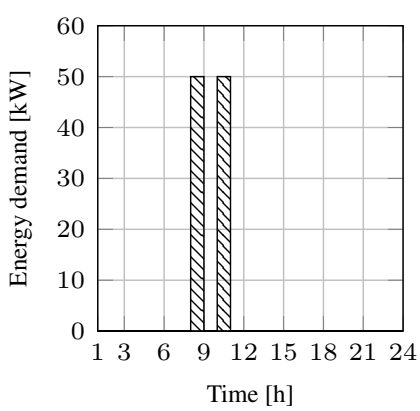

(a) Thermal demand
(b)Set-point

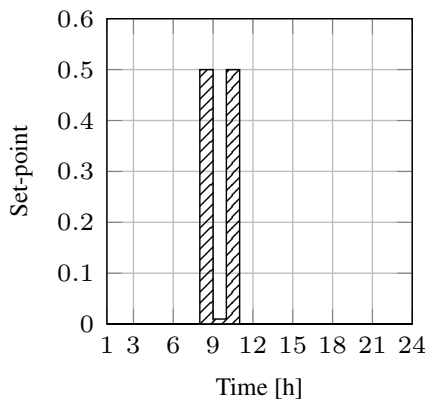

Figure 6: Representation of energy demand and set-point of the boiler as functions of time for validation case 5 .
The boiler is operated at $50 \%$ load during the demand peaks and remains at idle from 9 a.m to 10 a.m. (see Figure 6) as required by the minimum stay constraint, further demonstrating the ability of the heuristic to deal with constraints that connect different time-steps. (a) Thermal demand



(c) Set-point of boiler 1



(b) Efficiency of the boilers

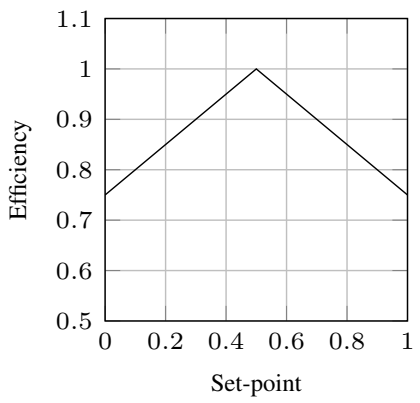

(d) Set-point of boiler 2



Figure 7: Representation of the energy demand, efficiency, and set-point of the boilers for validation case 6 .

Case 6. The thermal energy demand reported in Figure 7(a) is satisfied through 2 identical fuel boilers with a nominal power of $50 \mathrm{~kW}$. The efficiency curve of the boilers is reported in Figure 7(b) as a function of the set-point. Thermal storage is not considered as well as ignition costs and minimum stay constraints.

This test is designed to stress the capability of the methodology to deal with a non linear objective function, searching for minima that are not on the boundary of the domain. In fact, while one boiler could satisfy the peak thermal demand (that would be a solution at the boundary of the domain), both heat generators are operated at part load (see Figures 7(c) and 7(d)) to maximize the system efficiency and the optimum is found within the search domain.

Case 7. The energy demand and the power plant configuration are the same of case 6 , except for the cold start cost, which is now $c_{\mathrm{on}}=10 €$ for both boilers. The fuel costs $1 € / \mathrm{kg}$ and its lower heating value is $36 \mathrm{MJ} / \mathrm{kg}$.

Because of the cold start cost, only one fuel boiler is utilized (i.e. boiler 2) and strictly follows the energy demand, despite the efficiency is reduced at full load as shown in Figure 8. The resulting fuel cost is $c_{\text {fuel }}=15.8 €$. Such a cost could be reduced to $12.5 €$ utilizing the control strategy of case 6 , that maximizes the system efficiency, but the reduction of fuel costs 

from the ignition of the boiler number 1

(a) Set-point of boiler 1

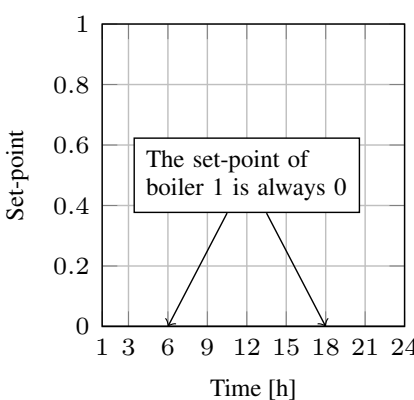

(b) Set-point of boiler 2

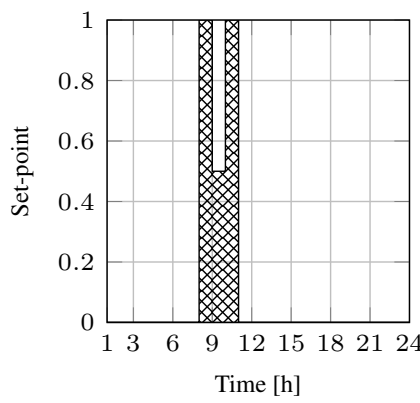

Figure 8: Representation of the set-point of the boilers as a function of time for validation case 7 .

Case 8. We consider here a plant composed of a $100 \mathrm{~kW}$ heat pump with constant coefficient of performance $\mathrm{COP}_{\mathrm{HP}}=1$ and of a thermal storage system with the same maximum power. The capacity of the thermal reservoir is $267 \mathrm{kWh}$ and the round trip efficiency of the storage process is set to 1 . Electricity is acquired from the grid and its cost varies between $0.5 € / \mathrm{kWh}$ and $1.0 € / \mathrm{kWh}$ (see Figure 9(a)). The electricity cost is minimized between 3 a.m. and 5 a.m.. The thermal energy demand is characterized by a $50 \mathrm{~kW}$ constant peak between 8 a.m. and 10 a.m. (see Figure 3(a)). (a) Electricity price



(b) Set-point

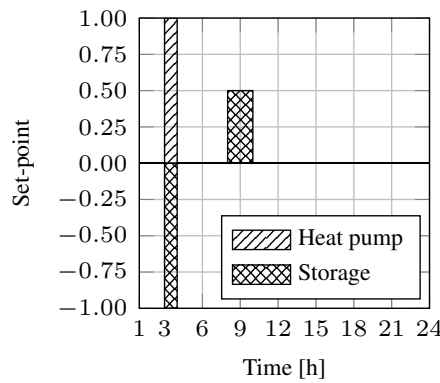

Figure 9: Representation of electricity price and set point of the heat pump and of the thermal storage as functions of time for validation case 8 .

As expected, according to the optimized control strategy, all the thermal energy necessary to fulfill the demand is produced by exploiting the heat pump at full power when the electricity cost is lower (i.e. between 3 a.m. and 5 a.m.) and stored (see Figure 9(b)). Then, the heat load is satisfied by modulating the power output of the thermal reservoir.

Case 9. The electricity demand reported in Figure 10(a) can be satisfied through the grid or using a generic electrical generator (e.g. an internal combustion engine or a fuel cell). The cost of the electricity drawn from the grid is $c_{\text {el,buy }}=1.00 € / \mathrm{kWh}$. The electrical generator has a constant efficiency equal to $\eta_{\mathrm{eg}}=$ 0.3 , and must operate for at least 6 consecutive hours. The minimum allowed set-point (i.e. the idle condition) is $50 \%$. The fuel lower heating value is $\mathrm{LHV}=36 \mathrm{MJ} / \mathrm{kg}$ and its cost is $c_{\text {fuel }}=2.5 € / \mathrm{kg}$. Electricity produced in excess is not remunerated. (a) Energy demand

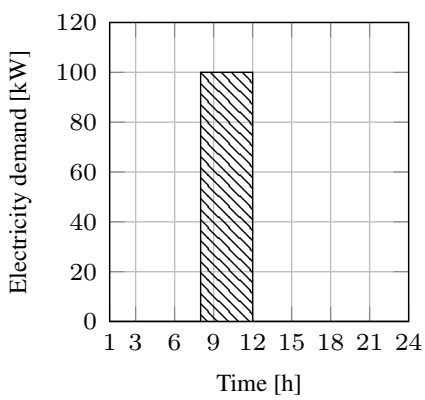

(b) Power generation

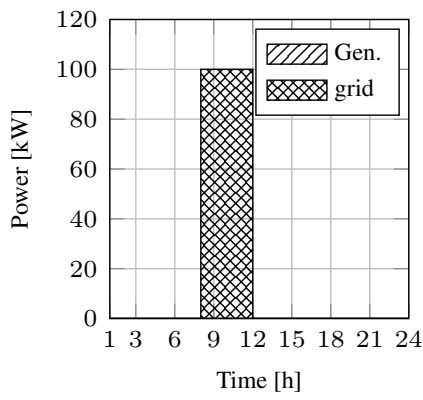

Figure 10: Representation of electricity demand and power production as functions of time for validation case 9

Despite the cost of the locally produced electricity, $c_{\mathrm{el}, \text { local }}={ }_{377}$ $0.83 € / \mathrm{kWh}$, is lower compared to one required by the grid, the generator is not utilized and all the power is acquired from the grid, as evidenced in Figure 10(b). In fact, running the generator at idle for two additional hours, as required by the constraint $\tau_{\text {on }}$, costs $83 €$, while the saving obtained thanks to the difference between $c_{\mathrm{el}, \text { local }}$ and $c_{\mathrm{el} \text {,buy }}$ during the 4 hours of electricity demand, is only $68 €$.

Case 10. The energy demand, the power plant, and the cost of electricity acquired from the grid are the same of case 9 . The fuel cost is reduced to $c_{\text {fuel }}=2.0 € / \mathrm{kg}$. (a) Energy demand

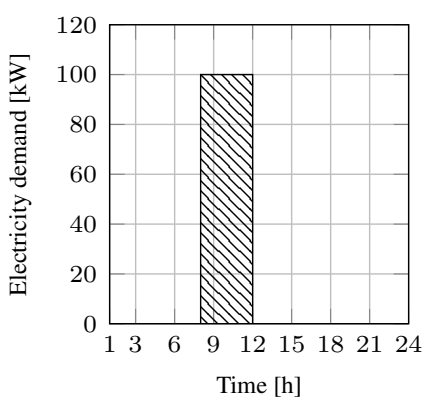

(b) Power generation

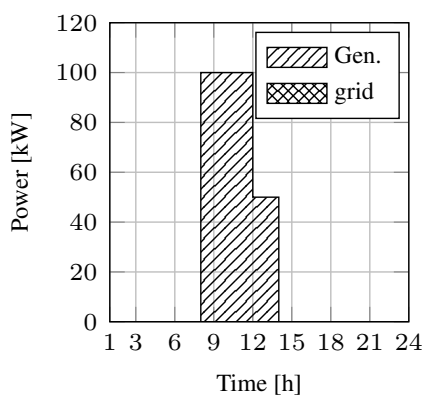

Figure 11: Representation of electricity demand and power production as functions of time for validation case 10 .

Having reduced the fuel cost, the generator is now operated for 6 hours (see Figure 11): 4 hours at full power to satisfy the energy demand, and 2 hours at idle to fulfill the minimum stay constraint. The total cost of running the generator for 6 hours is $333 €$, while acquiring the electrical power from the grid would have cost $416 €$.

Case 11. In this last validation case, we present a realistic application for the proposed methodology: a cogeneration plant including a CHP prime mover (e.g. an internal combustion engine or a fuel cell), a fuel boiler, and a thermal storage. The CHP prime mover develops a maximum electrical power of 
$100 \mathrm{~kW}$, with $30 \%$ electrical efficiency, $45 \%$ thermal efficiency, and its minimum allowed load is $50 \%$. The fuel boiler maximum power is $40 \mathrm{~kW}$ and its efficiency is equal to 1 . The thermal storage has a capacity of $166 \mathrm{kWh}$ and can exchange up to $40 \mathrm{~kW}$ of thermal power. The cost of the electricity from the grid is $c_{\mathrm{el}, \mathrm{buy}}=1.00 € / \mathrm{kWh}$. The fuel cost and LHV are $3.1 € / \mathrm{kg}$ and $36 \mathrm{MJ} / \mathrm{kg}$ respectively, for both the boiler and the cogenerative engine. (a) Energy demand

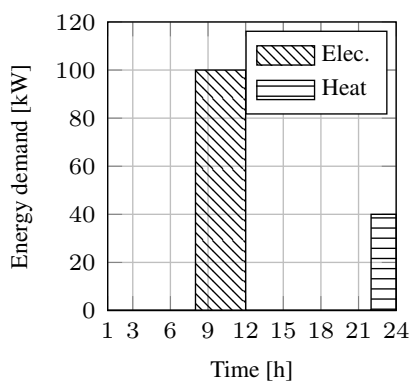

(b)Set-point

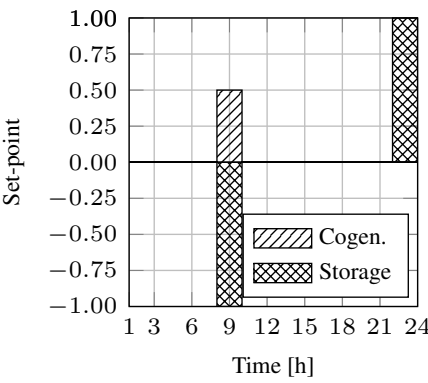

Figure 12: Representation of energy demand and set-point of the boiler and of the heat storage as functions of time for validation case 11 .

The energy demand, reported in Figure 12(a), is characterized by a $100 \mathrm{~kW}$ request of electrical power from 8 a.m. to 11 a.m. and by a $40 \mathrm{~kW}$ heat demand from 10 p.m. to 12 p.m.. Electricity eventually produced in excess is not remunerated.

This test case is designed such that, if we do not consider the value of the thermal energy, the cost of the electricity produce by the power plant $\left(c_{\text {el, local }}=1.03 € / \mathrm{kWh}\right)$ is slightly larger than $c_{\mathrm{el} \text {, buy }}$. Such a cost difference is more then compensated if the cogenerated heat can be utilized. Similarly, the production of thermal energy through cogeneration is convenient only if electricity can be utilized to satisfy the energy demand. In fact, the cost of heat produced through the cogenerator is $0.465 € / \mathrm{kWh}$, while the boiler requires only $0.310 € / \mathrm{kWh}$.

Figure 12(b) shows that, in this case, the rule based control strategies, such as thermal tracking or electrical tracking, that are usually employed for such systems, are not effective. The cogenerator is utilized to produce the heat required by the energy demand. The unit cost difference is compensated by directly consuming the produced electricity. Thereafter, the cogenerator must be operated during the hours of electricity demand. Since electrical and thermal loads are not contemporary, heat is first stored and then released to satisfy the heat demand. Even though the prime mover could produce all the necessary heat running for one hour at $60 \%$ load, it must operate for at least 2 hours because the thermal storage can accumulate only $40 \mathrm{~kW}$ of thermal power. As a consequence, it operates at $50 \%$ load, that is the minimum allowed set-point from 8 a.m to 10 a.m, as reported in Figure 12(b).

\section{Application of the proposed methodology to a realistic scenario}

In this section we utilize the methodology previously described to assess the effective performance of an innovative
CHP plant based on automotive PEM fuel cells, schematically represented in Figure 13 in a realistic scenario. The PEMFC converts natural gas into electricity and thermal energy that are utilized to fulfill the energy demand of a small hotel.

\begin{tabular}{c|cc|cc} 
& \multicolumn{2}{|c|}{$100 \mathrm{~kW} \mathrm{FC}$} & \multicolumn{2}{c}{$50 \mathrm{~kW} \mathrm{FC}$} \\
\hline Year & Min Cost & Min PEC & Min Cost & Min PEC \\
\hline 2016 & Case A & Case C & Case D & Case F \\
2012 & Case B & & Case E &
\end{tabular}

Table 1: Summary of the scenarios considered for the test case.

We optimize the plant control strategy hour by hour for a whole year (i.e. for 8760 time-steps). Then, we evaluate the effectiveness of the power plant in terms of economic sustainability, energy saving, and $\mathrm{CO}_{2}$ emissions. We simulate 6 scenarios that differs in energy cost (i.e. costs of years 2012 and 2016), size of the prime mover (i.e. $50 \mathrm{~kW}$ and $100 \mathrm{~kW}$ ), and management policy (i.e. minimum cost and minimum PEC.) The considered combinations are systematized in Table 1.

\subsection{Power plant description}

The idea of utilizing an automotive derivative fuel cell as prime mover for a CHP plant was introduced in [65]. Therein, the plant performance was also determined through a validated numerical modeling.

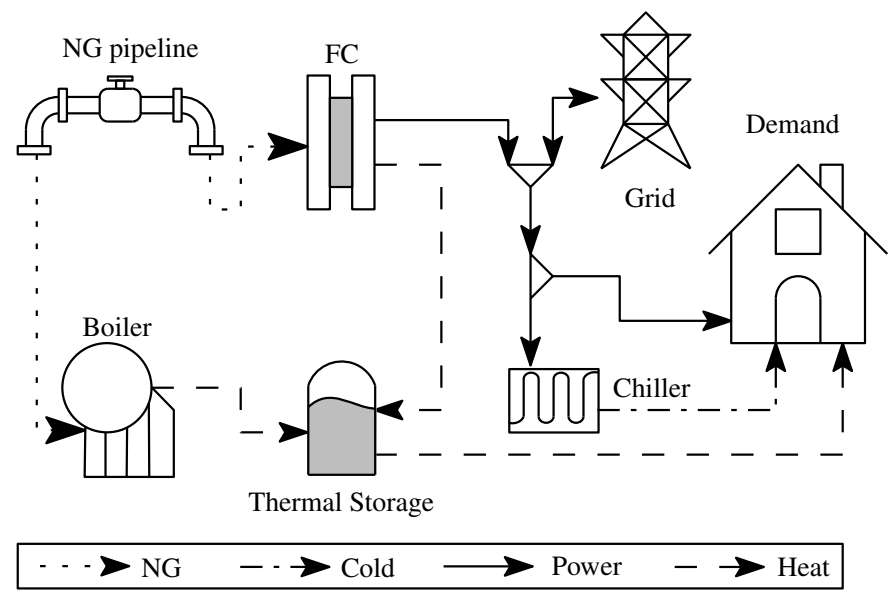

Figure 13: Schematic of the CHP plant in study including all the relevant components and connections.

The prime mover of the CHP plant in study is a low temperature PEM fuel cell. The electricity is generated within the FC by the catalytic oxidation of pure hydrogen. The FC operates at a temperature of $80^{\circ} \mathrm{C}$ and low grade thermal energy can be generated from the waste heat. Despite the relatively low temperature, such thermal energy can be profitably utilized in civil and commercial applications for space heating and domestic hot water production. A fuel processor, described in details in [65], produces high purity $\mathrm{H}_{2}$ from natural gas, such that the $\mathrm{CHP}$ plant can be directly connected to the natural gas distribution pipeline. 


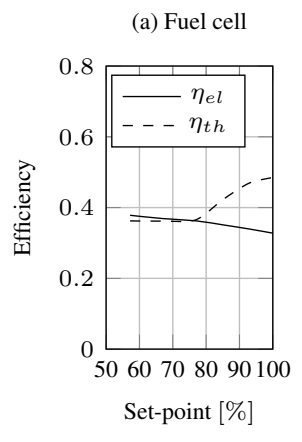

The performance of this energy system was estimated in [65], through a validated thermo-chemical model developed within the AspenPlus ${ }^{\circledR}$ [66] modeling environment.

The net electrical and thermal efficiency of the cogenerative FC are reported in Figure 14(a) as functions of the set point. The minimum FC load is $50 \%$ for a limitation of the fuel processor at lower hydrogen flow rates.


Figure 14: Efficiencies of the relevant components of the CHP plant as functions of the set-point: (a) Fuel cell; (b) Boiler; (c) Mechanical chiller.

A $170 \mathrm{~kW}$ natural gas burner and a $125 \mathrm{~kW}$ mechanical chiller are also included in the energy system, as evidenced in Figure 13. The Boiler efficiency and the chiller coefficient of performance (COP) are retrieved from literature [41] and reported in Figure 14(b) and in Figure 14(c) as functions of the set-point.

To increase the flexibility of the plant, releasing the FC and the boiler from thermal tracking, we also included a $511 \mathrm{kWh}$ thermal storage, capable of satisfying the peak heat demand for for 3 hours. The heat storage round-trip efficiency is $90 \%$.

The power plant is grid connected and electricity can both be acquired or sold to the grid. The excess of electricity production is remunerated at the electricity stock market price, that varies on a hourly basis throughout the year. Costs and prices will be reported in section 3.2.

\subsection{Description of the surrounding energy system}

The surrounding energy system contributes to the effective performance of the power plant through the costs of electricity and fuels, the primary energy factors (PEFs), and the emission factors. Energy prices largely determine the optimal control strategy, in case of economic optimization [35]. The efficiency of the encompassing energy environment influences the impact of the CHP plant in terms of energy saving and emission reduction [10], and significantly contribute to the determination of the optimal control strategy if PEC minimization is employed.

Primary energy factors and $\mathrm{CO}_{2}$ emission factors of the energy streams entering and exiting the boundaries of the considered energy system are necessary to evaluate the environmental impact of the CHP plant. Herein, we assumed a PEF of NG equal to 1.1 [61] and a PEF of electricity equal to 2.45 [68] according to the average efficiency of the Italian energy system. The $\mathrm{CO}_{2}$ emission factor is set to $0.1998 \mathrm{~kg} / \mathrm{kWh}$ for $\mathrm{NG}$ and to $0.4332 \mathrm{~kg} / \mathrm{kWh}$ for the electricity drawn from the grid [69].

Electricity and natural gas unit costs are also obtained from the Italian market $[67,70,71]$. To assess the effects of the en- ergy market conditions, we consider 2 combinations of unit energy prices and costs.

Scenario 1. The unit cost of electricity is $c_{\mathrm{el}, \text { buy }}=0.1556 € / \mathrm{kWh}_{510}$ according to the regulations for the Italian electricity market for 511 year 2016 [71]. The electricity eventually produced in excess is 512 remunerated at the electricity stock market price $c_{\text {el,sell }}$. Such ${ }_{513}$ a price is retrieved for year 2016 from [67] and is reported in 514


out the year being its average value $\overline{c_{\mathrm{el}, \mathrm{sell}}}=42.8 € / \mathrm{MWh}$ and $\quad 516$ its standard deviation is $\sigma_{c_{\mathrm{el}, \mathrm{sell}}}=13.0 € / \mathrm{MWh}$. The cost of ${ }_{517}$ natural gas is set to $8.67 € / \mathrm{GJ}$ as reported in [70].

Scenario 2. We assess the effects of the energy prices level by assuming the electricity and NG costs of year 2012 in Italy. Specifically, $c_{\mathrm{el}, \text { buy }}=0.1778 € / \mathrm{kWh}[71]$, and $c_{\mathrm{el}, \text { sell }}$ is reported in Figure 16 [67]. In this scenario, $\overline{c_{\mathrm{el}, \text { sell }}}>=75.5 € / \mathrm{MWh}_{522}$ and $\sigma_{c_{\mathrm{el}, \mathrm{sell}}}=22.2 € / \mathrm{kWh}$. We note that both the average price ${ }_{523}$ and the variability are significantly larger compared to scenario 1. Also the cost of NG is much larger compared to scenario 1, being $c_{\text {gas }}=11.00 € / \mathrm{GJ}[70]$.

\subsection{Energy demand}

The hourly electricity, heat, and chilling energy demands for 16 commercial reference buildings are available in the "commercial reference buildings" database [72] of the US Department of Energy (DOE) for more than 1000 locations (i.e. different climatic conditions) within the US. For this test case we selected the energy demand of a small hotel in the city of Baltimore, that is reported in Table 2 .

\begin{tabular}{l|ccc} 
& Minimum & Average & Maximum \\
\hline Electricity [kW] & 31 & 56 & 93 \\
Heat $[\mathrm{kW}]$ & 0 & 31 & 168 \\
Chilling $[\mathrm{kW}]$ & 0 & 29 & 123
\end{tabular}

Table 2: Minimum, average, and maximum energy demand for a small hotel in the heating based climatic condition. Data are retrieved from [72].

With about 2500 heating degrees days per year and about 750 cooling degrees days per year, Baltimore is a representative city of the heating based climate [73]. In such a climate the need for heating in winter is large, but, during summer, cooling becomes an option at least for comfort. It is representative of most of the European territory, Canada, and central US [73].

The ratio between the thermal and electrical energy required (HoP) is an important parameter for the analysis of the performance of CHP plant. The chilling energy must be included within the electricity demand, because is produced through a mechanical chiller, as shown in eq. (6), where $E_{\mathrm{th}}, E_{\mathrm{el}}, E_{\mathrm{ch}}$ are the total thermal, electrical, and chilling energy required throughout the year, and $\overline{\mathrm{COP}}$ is the average coefficient of performance of the chiller. Specifically, $\overline{\mathrm{COP}}=3$ as evidenced in Figure 14(c).

$$
\mathrm{HoP}=\frac{E_{\mathrm{th}}}{E_{\mathrm{el}}+E_{\mathrm{ch}} / \overline{\mathrm{COP}}}=0.455 .
$$




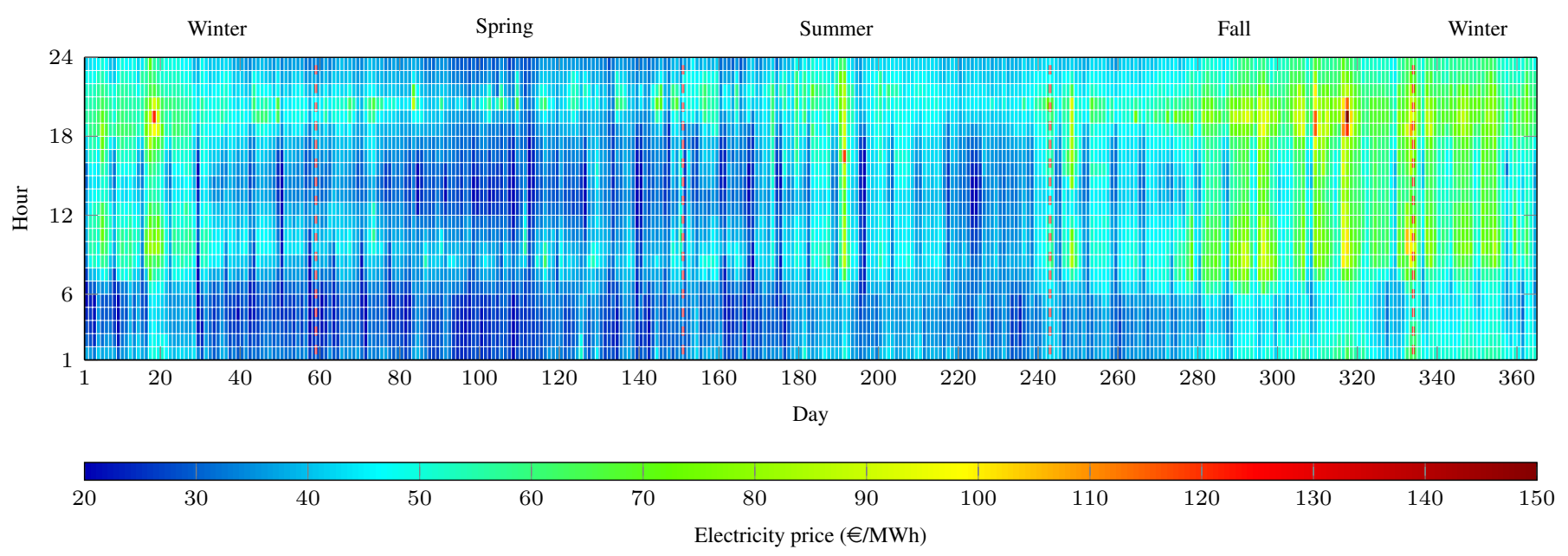

Figure 15: Representation of the price of the electricity sold to the grid as a function of the day of the year and of the hour for scenario 1 (year 2016). Data are retrieved from [67].

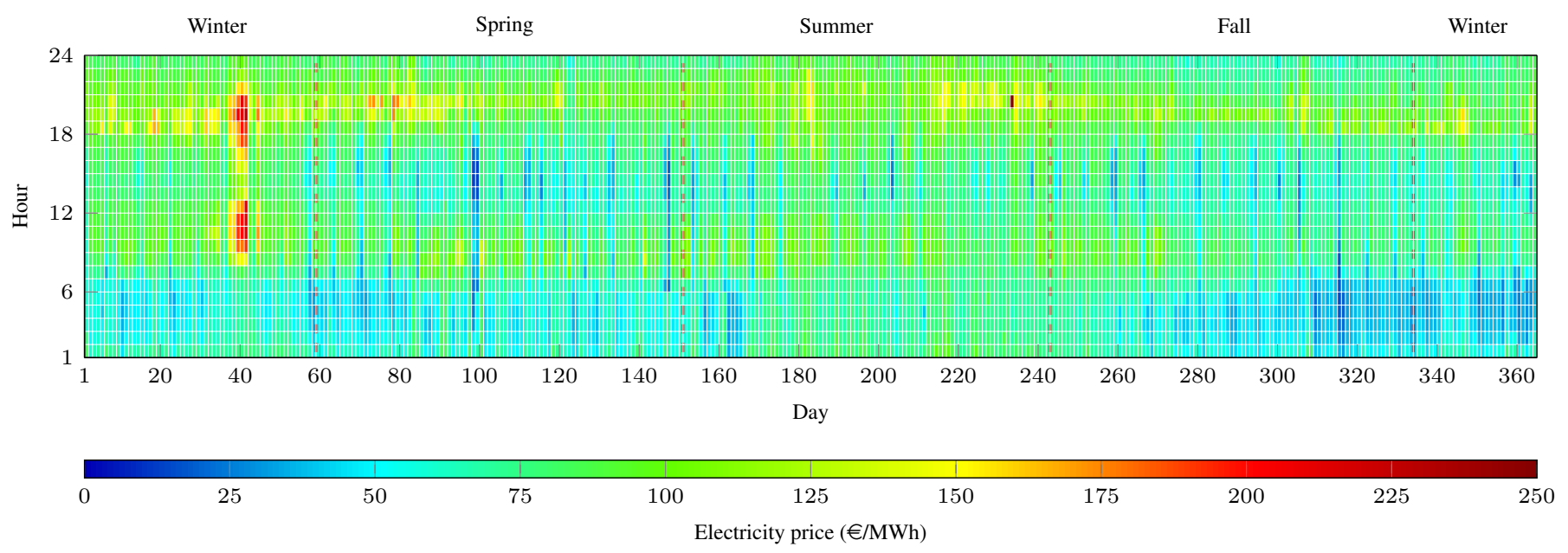

Figure 16: Representation of the price of the electricity sold to the grid as a function of the day of the year of the hour for scenario 2 (year 2012). Data are retrieved from [67].

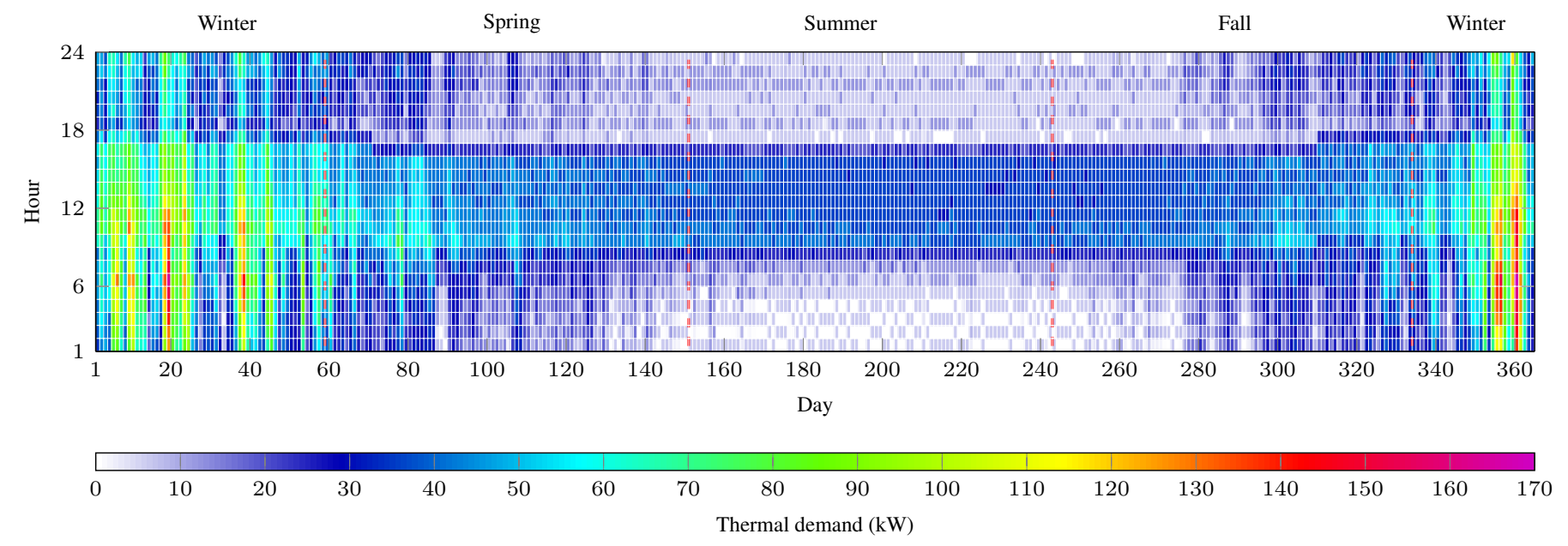

Figure 17: Representation of the heat demand as a function of the day of the year and of the hour for the considered test case. Data are retrieved from [72]. 




Figure 18: Representation of the electricity demand as a function of the day of the year and of the hour for the considered test case. Data are retrieved from [72].

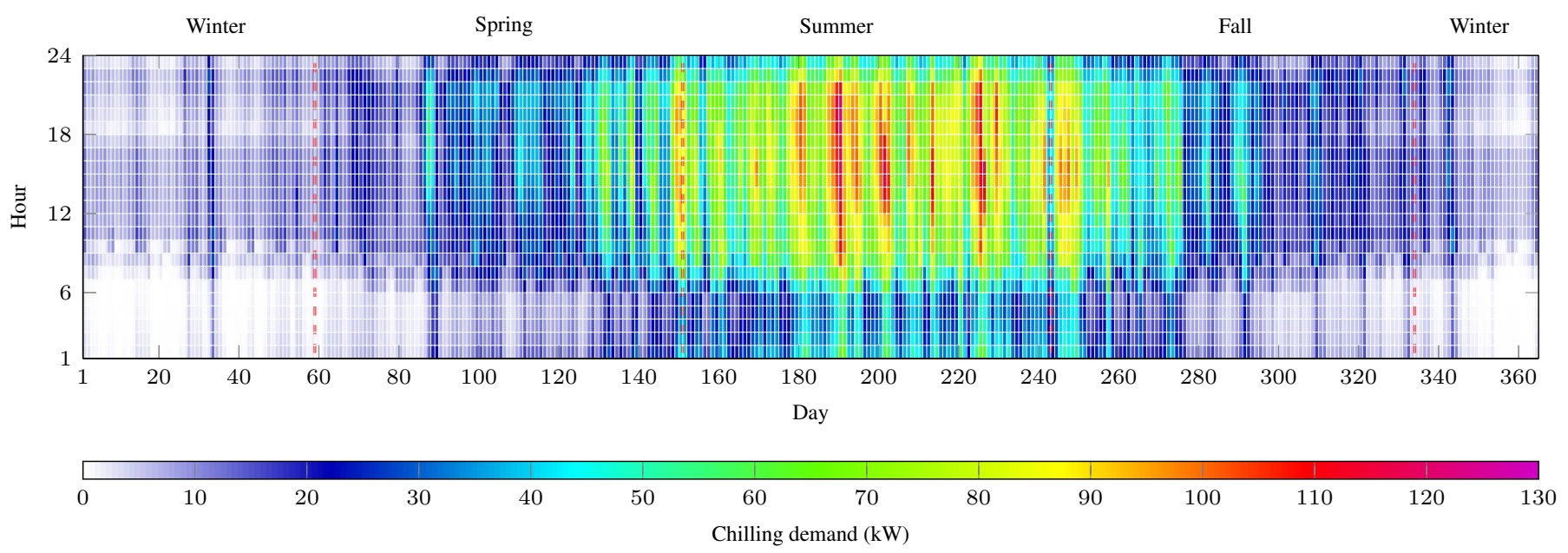

Figure 19: Representation of the chilling demand as a function of the day of the year and of the hour for the considered test case. Data are retrieved from [72].

During summer, the electrical demand overwhelms the heat request (see Figure 17 and 18), reducing the HoP below 0.5, despite during winter the average thermal demand is larger than the electrical one. During summer, also the chilling demand, reported in Figure 19, contributes to the reduction of the HoP. Thereof, the option of utilizing absorption chillers to convert the chilling demand into thermal demand might be considered to improve the performance of the CHP plant. This option was discarded here due to the low temperature of the heat produced by the fuel cell.

To support the discussion of the results we also introduce the parameter $\Theta$ that represents the number of equivalent hours necessary to fulfill the electrical demand utilizing the fuel cell. Such a parameter is calculated through the following equation

$$
\Theta=\frac{E_{\mathrm{el}}+E_{\mathrm{ch}} / \overline{\mathrm{COP}}}{P_{\mathrm{el}}}= \begin{cases}4880 \mathrm{~h} & \text { Cases A, B, C, } \\ 9760 \mathrm{~h} & \text { Cases D, E, F },\end{cases}
$$

where $P_{\mathrm{el}}$ is the electrical power of the FC. The $100 \mathrm{~kW} \mathrm{FC}$ must operate for about $55 \%$ of the year to completely satisfy the electricity and chilling demand, despite the maximum power request is slightly lower compared to the $\mathrm{FC}$ rated power. On the contrary, the $50 \mathrm{~kW} \mathrm{FC}$ is not sufficient to completely satisfy the electricity demand, since $\Theta>8760 \mathrm{~h}$ for Cases D, E, and F.

\subsection{Results and discussion}

The equipment state is discretized in 40 steps, which is to say that we assume a $2.5 \%$ load difference between consecutive set-points. The resulting total number of feasible set-points for the considered plant is $2.5 \times 10^{6}$. The proposed heuristic reduces the number of nodes of the graph associated to the optimization problem to $7 \times 10^{4}$. The computational time to determine the optimal control strategy is about $2.5 \mathrm{~h}$ on a personal computer equipped with one Intel i-7 processor with 4 cores, a frequency of $3.4 \mathrm{GHz}$, and $8 \mathrm{~GB}$ of RAM memory.

Without utilizing the heuristic, the total number of nodes and the corresponding number of arcs would have been $2.2 \times$ $10^{10}$ and $5.7 \times 10^{16}$, respectively. Few double precision real numbers, that allocates 8 bits each, are associated to each arc and node. Thereafter, the optimization problem requires the 
allocation of about $10^{6}$ TB of RAM, being thus completely impossible to solve with the nowadays available computational infrastructures.

\begin{tabular}{c|ccc} 
Case & Cost $[\mathrm{k} €]$ & PEC [GJ] & $\mathrm{CO}_{2}$ [Ton] \\
\hline A,C,D,F & 102 & 6.52 & 322 \\
B,E & 118 & 6.52 & 322
\end{tabular}

Table 3: Energy cost, primary energy consumption, and carbon dioxide emission for the reference case and for the two considered years.

The proposed power plant is compared to a reference scenario where electricity is acquired from the grid, a natural gas boiler produces the required thermal energy, and a mechanical chiller delivers the chilling power. The most relevant performance parameters of such a scenario are reported in Table 3.

\begin{tabular}{c|ccc} 
Case & Cost $[\mathrm{k} €]$ & PEC [GJ] & $\mathrm{CO}_{2}$ [Ton] \\
\hline A & 52.7 & 6.56 & 331 \\
B & 66.5 & 6.56 & 331 \\
C & 73.7 & 5.73 & 285 \\
D & 66.4 & 6.59 & 330 \\
E & 80.9 & 6.51 & 326 \\
F & 75.6 & 5.77 & 287
\end{tabular}

Table 4: Energy cost, primary energy consumption, and carbon dioxide emission for 1 year obtained through CHP for all the considered cases.

Table 4 reports the performance of the CHP plant for all the combinations of energy cost, FC design power, and control strategy. Cogeneration always reduces the total energy supply cost, but the minimum PEC control strategy should be utilized to have a significant reduction of energy consumption and of $\mathrm{CO}_{2}$ emissions. Managing a $100 \mathrm{~kW}$ FC through the minimum cost control strategy (cases A and B) yields the lower yearly cost. Such a cost increases by on average $25 \%$ reducing the size of the FC to $50 \mathrm{~kW}$ (Cases D and E). Switching from economic to PEC minimization increments the energy cost by $33 \%$ for the $100 \mathrm{~kW} \mathrm{FC} \mathrm{(cases} \mathrm{A} \mathrm{and} \mathrm{C)} \mathrm{and} \mathrm{and} \mathrm{by} 13 \%$ for the $50 \mathrm{~kW}$ one.

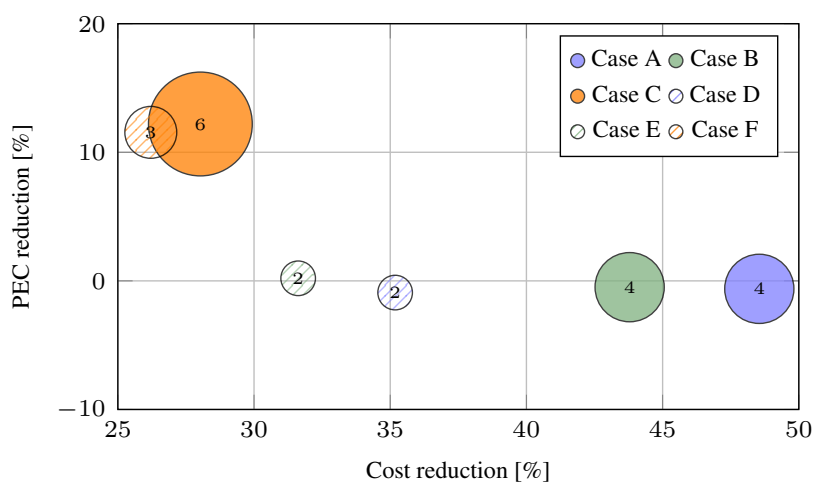

Figure 20: Comparison between the different test cases. The area of the circles is proportional to the pay back period, also reported as a number, and the center of the circles defines relative cost and PEC reduction.

For all the considered cases, the Pay Back Period (PBP) is calculated though eq. (8), where $i$ is the unit capital cost of the CHP plant.

$$
\mathrm{PBP}=\frac{\mathcal{I} \cdot P_{\mathrm{El}}}{\text { Reference Cost }- \text { Cost }} .
$$

Here, we assumed that $\mathcal{I}=2000 € / \mathrm{kW}$. Such a cost is much lower compared to the current market values [74-78]. However, it compares to the targets set by the Fuel Cells and Hydrogen Joint Undertaking (FCH-JU) [79] and to the estimations of the DOE [80].

Figure 20 allows a comprehensive evaluation of the proposed CHP plant configurations by reporting the relative PEC reduction, cost reduction, and the PBP in the same plot. Managing the $50 \mathrm{~kW}$ power plant with a PEC minimization strategy reduces the costs and the PEC by $26 \%$ and $12 \%$ respectively, compared to the reference scenario. With a PBP of 3 years, case $\mathrm{F}$ is the best overall performing design. Increasing the FC power to $100 \mathrm{~kW}$ leaves unaltered the PEC and slightly improves the relative cash flow. However, the larger PBP (6 years) might hinder the investment. Economic optimization significantly increments the relative cash flow with respect to PEC minimization, but it negatively affects the efficiency of the plant. In fact, the PEC reduction is slightly negative in all such cases except for case E. For cases A and B the PBP is also larger compared to case $\mathrm{F}$, due to the higher power of the FC.

Electricity and NG market costs impact the economic performance while having a negligible effect on the PEC as evidenced comparing case A to case B and case D to case E. Thereafter, for PEC minimization we utilized only the 2016 energy prices. In 2016 , the ratio $\eta^{*}=c_{\text {el, buy }} / c_{\text {gas }}=5.0$ while, in 2012, $\eta^{*}=4.5$. As a consequence, cases A and D the have a larger relative cost reduction compared to cases $\mathrm{B}$ and $\mathrm{E}$ respectively, despite the energy prices in 2012 were higher compared to year 2016.

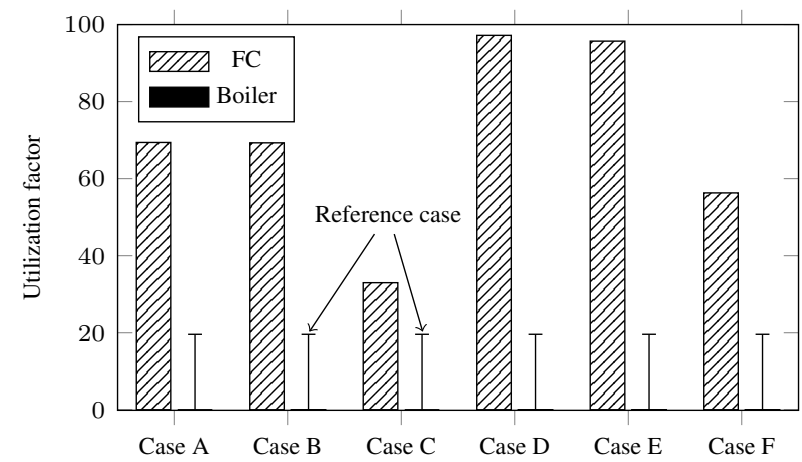

Figure 21: Utilization factors of the fuel cell and the boiler for all the test cases.

The cost of locally produced electricity $\left(c_{\mathrm{el}, \text { local }}\right)$ varies in the range $[82 € / \mathrm{MWh}, 95 € / \mathrm{MWh}]$ with the $2016 \mathrm{NG}$ prices and in the range $[104 € / \mathrm{MWh}, 131 € / \mathrm{MWh}]$ assuming the 2012 $c_{\text {gas }}$. Such costs are considerably lower compared to $c_{\mathrm{el}, \mathrm{buy}}$. Thus, self consumption of electricity is economically convenient with respect to decentralized production, and economic optimization (cases A,B,D, and E) yields a very large FC utilization factor $\left(\mathrm{UF}_{\mathrm{FC}}\right)$, namely from $65 \%$ to $97 \%$ as shown 


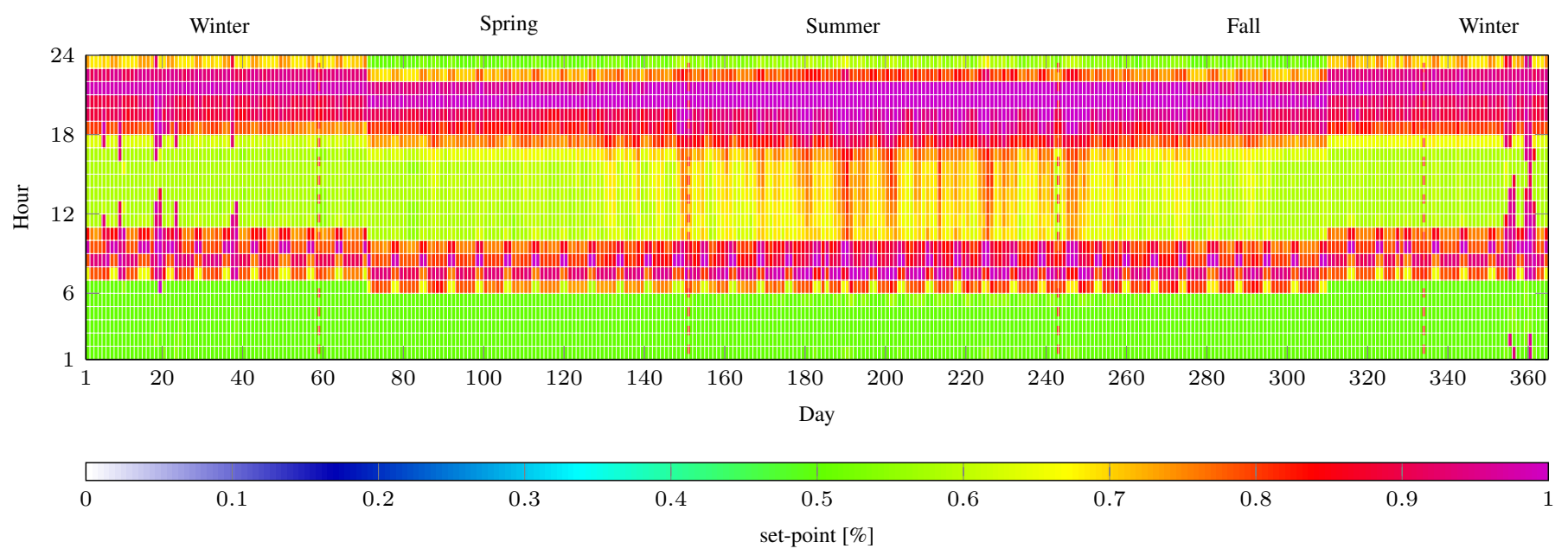

Figure 22: Representation optimal set-point as a function of the day and of the hour for case A.

in Figure 21). Specifically, with a FC of $100 \mathrm{~kW}$ power the $\mathrm{UF}_{\mathrm{FC}}>\Theta$ and the FC is never turned off (see, Figure 22). Comparing Figure 22 to Figure 18 we note that all the electricity required by the hotel is produced by the FC. During off-peak hours there is an over production of electricity because the FC, operating an the minimum allowed set-point (i.e. 50\%), generates an electrical power greater than the electricity demand. The electricity produced in excess is sold to the grid even if $c_{\mathrm{el}, \text { local }}<c_{\mathrm{el}, \text { sell }}$. The Partial recovery of heat and the large imbalance between $c_{\mathrm{el}, \text { local }}$ and $c_{\mathrm{el} \text {, buy }}$ compensates such a difference. The fuel cell operates at full load during peak hours and when chilling demand is high, as clearly detectable in Figure 19. Economic optimization operates the $50 \mathrm{~kW} \mathrm{FC} \mathrm{almost}$ always at full power (UF > 95\%) to fulfill the electricity demand.



Figure 23: Thermal energy production for the considered cases. The shaded area represents the heat demand.

Cogeneration satisfies the whole heat demand in all the scenarios, as shown in Figure 21, which evidences that the utilization factor of the boiler $\mathrm{UF}_{\mathrm{boi}}=0$, and in Figure 23, which clearly shows that the heat production is always greater than the heat demand. The hotel utilizes less than $50 \%$ of the produced thermal energy when the FC follows an economically optimal control strategy, due to the low value of HoP combined with the relatively high $\mathrm{UF}_{\mathrm{FC}}$.
Since $\eta_{\mathrm{FC}} / \mathrm{PEF}_{\mathrm{NG}}<1 / \mathrm{PEF}_{\text {grid }}$ an effective heat recovery is necessary to reduce the PEC. Thereof, economic optimization does not guarantee that the CHP plant reduces the PEC of the hotel (see Figure 20 and Table 4). Nevertheless, an effective energy saving with respect to the business as usual scenario is obtained with the same power plant with a management strategy that minimizes the PEC. Such a management policy reduces $\mathrm{UF}_{\mathrm{FC}}$ to improve the heat recovery, as evidenced in Figure 21 and Figure 23. In cases $\mathrm{C}$ and F, the FC heat generation is close to the energy demand. Thus, the plant total efficiency is higher than in the other cases, as shown in Figure 20. Generally speaking, PEC minimization reduces the the fuel cell load with respect to economic optimization (see Figure 22 and Figure 24). Moreover, comparing Figure 24 to Figure 18 and Figure 17, we note that the FC is turned off when thermal demand is low (i.e. during the night in the warm seasons), independently from of the electricity demand. On the other hand, the FC operates at high load during winter in the morning and the central part of the day, when the thermal demand is high.

\section{Conclusion}

In this paper we presented a methodology to determine the optimal control strategy for complex energy systems including cogeneration and trigeneration plants, smart cities and advanced energy converters (e.g. fuel cells). Such a methodology accounts for the nonlinear and dynamic behavior of the energy systems, allowing a generic mathematical relationship between the efficiency and the set-point, and introducing the constraints and efficiency penalty related to cold start. Energy storage and deferred usage is also considered. To this aim we built on the model developed in $[22,35,53]$ by introducing an heuristic procedure that significantly reduces the computational effort required for optimization. The procedure developed herein boosts the range of possible applications of the original methodology by cutting the computational time by several orders of magnitude. 


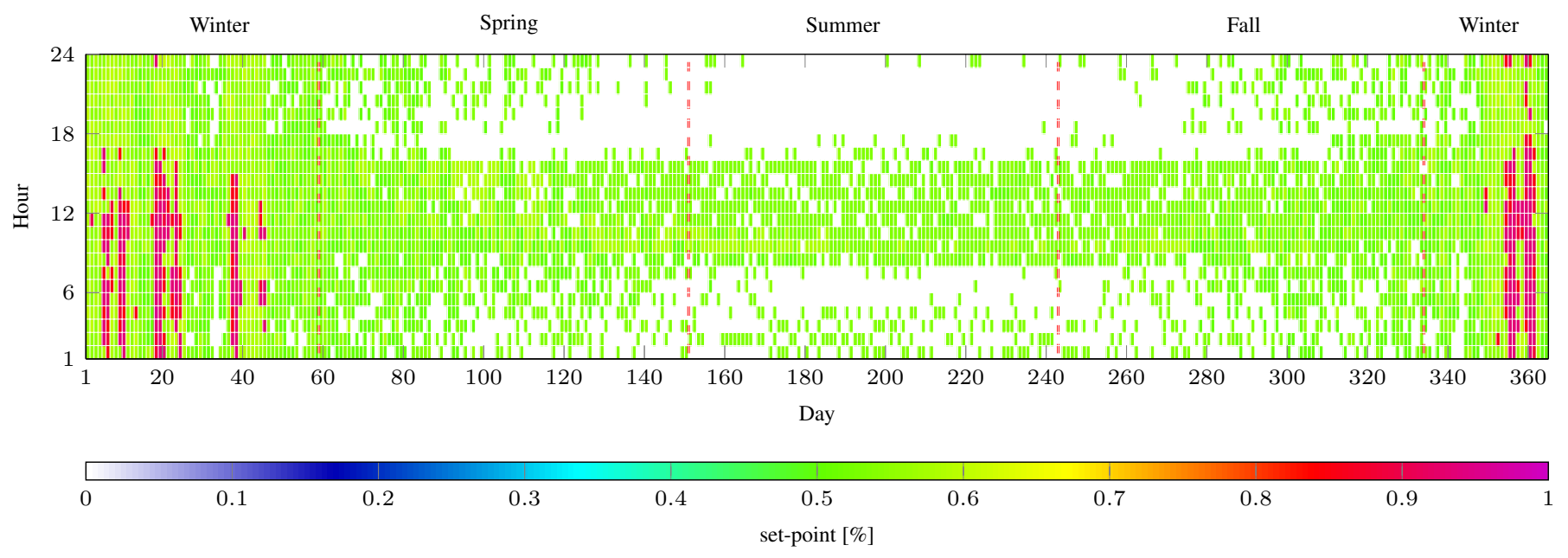

Figure 24: Representation optimal set-point as a function of the day and of the hour for case E.

We first validated the heuristic through 11 test cases specifically designed to evidence eventual shortcomings. These tests demonstrated that the heuristic does not introduce any approximation with respect to the original methodology. The procedure correctly determines the global optimum.

Then, we applied the methodology to a realistic test case: the optimization of the control strategy of an innovative cogeneration plant based on a low temperature PEM fuel cell. We assumed that the CHP plant is utilized to satisfy the energy demand of a small hotel and we considered various scenarios combining different management policies (i.e. minimum cost or minimum PEC), power plant configuration (i.e. $50 \mathrm{~kW}$ and $100 \mathrm{~kW}$ fuel cell), and energy costs (i.e. relative to year 2012 and 2016). For each combination, we determined the optimal control strategy for 8760 consecutive time intervals (i.e. for a whole year). The computation took about 2.5 hours on an average quality desktop computer and would have been impossible even on a large computer cluster though the original methodology, due to the huge amount of random access memory required.

The analysis of the simulation results highlighted the potential applications of the proposed methodology that include the design of new power plants, the optimal management of existing systems, the evaluation of the effects of a plant on the encompassing energy system and environment, and the assessment of emerging technologies.

This methodology supports the design of a new power plant, and in particular of a DG unit, by calculating the relevant costs and revenues to be compared to the capital investment to assess its economic sustainability. Its application to a given plant and energy management scenario (i.e. the combination of energy prices, system efficiency and management policy) directly yields the yearly cash flow, which can be compared to the investment to determine its profitability. It also evaluates the system efficiency and environmental impact that might be considered as concurrent factors for the design of a power plant. In this respect, the proposed test cases evidenced, through the results reported in Figure 20, that the combination of a $50 \mathrm{~kW}$ fuel cell (i.e. designed on the average electrical power demand) and a management policy based on the minimization of the primary energy consumption is the best design compromise. It has $P B P=3 \mathrm{y}$, reducing the cost by $26 \%$ and the PEC by $11 \%$ with respect to the business as usual. It might be argued also that the hotel is not the best energy demand for the selected cogeneration technology (i.e. a low temperature FC) due to the low HoP, which hinder the heat recovery, thus requiring a dedicated control strategy to improve the energy performance compared to separate production of electricity and heat. In fact, Figure 23 shows that, even in the most efficient case (i.e. Case F), the cogenerated heat is $20 \%$ higher compared to the demand.

The discussion on the test-case results confirmed that the control strategy fundamentally determines the plant performance, as already evidenced in $[10,34,60]$. Significant improvements of the system efficiency and/or economy might be obtained by improving the management policy without changing the energy conversion technology. Specifically, it is evidenced that, since the relatively low HoP of the hotel energy demand penalize the total efficiency of the CHP plant, the minimum PEC control strategy must be assumed, in this case, to reduce the global energy consumption with respect to the reference scenario. Specifically, PEC minimization reduces the energy consumption by $13 \%$ compared to economic optimization.

The optimization results also gave a detailed report of the power plant operations (e.g. the instantaneous set-point, the UF of the subsystems, the electrical and thermal productions, etc) that could be utilized by the technology developers to highlight the strengths and weaknesses of a given prime mover. The high flexibility related to the good part load efficiency, and the relatively high efficiency for small power plants are among the FCs strengths according to the presented results. On the other hand, the high cost of natural gas and the low grade of the cogenerated thermal energy, which hampers the utilization of absroption chillers, are the evidenced weaknesses. The latter, for instance, might envisage the opportunity to dedicate some effort to develop absorption technologies that convert low grade heat into chilling energy. 
Finally, also policy makers could leverage on the proposed methodology to assess the effectiveness of the different national energy systems. The presented test case demonstrated that, in the Italian energy market, the generally high energy costs generate high cash flows fostering investments on DG. On the other hand, the very high ratio between electricity and NG costs for final users discourage the energy efficiency of DG plants. In fact, locally produced electricity is $16 \%$ to $54 \%$ less expensive compared to grid electricity and cogeneration is convenient also with relatively low efficiencies and with low waste heat recovery.

\section{Acknowledgment}

This project has received funding from the Fuel Cells and Hydrogen Joint Undertaking under grant agreement $\mathrm{N}^{\circ} 671396$. This Joint Undertaking receives support from the European Union's Horizon 2020 research and innovation program and United Kingdom, Germany, Greece, Croatia, Italy, Switzerland, Norway. Swiss partners are funded by the State Secretariat for Education, Research and Innovation of the Swiss Confederation.

\section{References}

[1] UNFCCC, United nations framework convention on climate change (2017).

URL http: //unfccc.int/kyoto_protocol/background/ items $/ 2879$.php

[2] The European Parliament and the Council of the European Union, Directive 2012/27/eu of the european parliament and of the council of 25 october 2012 on energy efficiency, amending directives 2009/125/ec and 2010/30/eu and repealing directives 2004/8/ec and 2006/32/ec, Official Journal of the European Union.

[3] Iternational Energy Agency, World energy balances overview (2017).

[4] Iternational Energy Agency, Key world energy statistics (2017).

[5] Eurostat, Panorama of energy. Energy statistics to support EU policies and solutions, Eurostat, 2009.

[6] International Energy Agency, World energy investment 2017 (2017). URL https: //www. iea.org/publications/wei2017/

[7] A. Franco, P. Salza, Strategies for optimal penetration of intermittent renewables in complex energy systems based on techno-operational objectives, Renewable Energy 36 (2) (2011) 743 - 753.

[8] R. Cozzolino, L. Tribioli, G. Bella, Power management of a hybrid renewable system for artificial islands: A case study, Energy 106 (2016) 774-789.

[9] K. Lau, M. Yousof, S. Arshad, M. Anwari, A. Yatim, Performance analysis of hybrid photovoltaic/diesel energy system under malaysian conditions, Energy 35 (8) (2010) 3245 - 3255.

[10] A. L. Facci, V. Cigolotti, E. Jannelli, S. Ubertini, Technical and economic assessment of a sofc-based energy system for combined cooling, heating and power, Applied Energy 192 (Supplement C) (2017) 563 - 574.

[11] Building Technologies Office, Buildings (2016 (accessed March 11, 2016)).

$$
\text { URL http: //energy.gov/eere/efficiency/buildings }
$$

[12] Indirect methodologies to estimate energy use in vehicles: Application to battery electric vehicles, Energy Conversion and Management 124 (2016) $116-129$.

[13] Iternational Energy Agency, Combined heat and power evaluating the benefits of greater global investment (2008).

[14] H. Onovwiona, V. Ugursal, Residential cogeneration systems: review of the current technology, Renewable and Sustainable Energy Reviews 10 (5) (2006) $389-431$.

[15] G. Chicco, P. Mancarella, Distributed multi-generation: A comprehensive view, Renewable and Sustainable Energy Reviews 13 (3) (2009) 535 551.
[16] D. Sánchez, J. M. De Escalona, B. Monje, R. Chacartegui, T. Sánchez, Preliminary analysis of compound systems based on high temperature fuel cell, gas turbine and organic rankine cycle, Journal of Power Sources 196 (9) (2011) 4355-4363.

[17] X. Zhao, L. Fu, F. Li, H. Liu, Design and operation of a tri-generation system for a station in china, Energy Conversion and Management 80 (Supplement C) (2014) 391 - 397.

[18] A. Gil, M. Medrano, I. Martorell, A. Lázaro, P. Dolado, B. Zalba, L. F. Cabeza, State of the art on high temperature thermal energy storage for power generation. part 1âconcepts, materials and modellization, Renewable and Sustainable Energy Reviews 14 (1) (2010) 31-55.

[19] M. Medrano, A. Gil, I. Martorell, X. Potau, L. F. Cabeza, State of the art on high-temperature thermal energy storage for power generation. part 2âcase studies, Renewable and Sustainable Energy Reviews 14 (1) (2010) 56-72.

[20] A. L. Facci, D. Sánchez, E. Jannelli, S. Ubertini, Trigenerative micro compressed air energy storage: Concept and thermodynamic assessment, Applied Energy 158 (2015) 243 - 254.

[21] V. Marano, G. Rizzo, F. A. Tiano, Application of dynamic programming to the optimal management of a hybrid power plant with wind turbines, photovoltaic panels and compressed air energy storage, Applied Energy 97 (0) (2012) 849-859, energy Solutions for a Sustainable World - Proceedings of the Third International Conference on Applied Energy, May 16-18, 2011 - Perugia, Italy.

[22] A. L. Facci, L. Andreassi, S. Ubertini, E. Sciubba, Analysis of the influence of thermal energy storage on the optimal management of a trigeneration plant, Energy Procedia 45 (2014) 1295-1304.

[23] J. Lizana, R. Chacartegui, A. Barrios-Padura, C. Ortiz, Advanced lowcarbon energy measures based on thermal energy storage in buildings: A review, Renewable and Sustainable Energy Reviews 82 (2018) 3705 3749 .

[24] S. Ubertini, A. L. Facci, L. Andreassi, Hybrid hydrogen and mechanical distributed energy storage, Energies 10 (12).

[25] C. Boigues-Muñoz, G. Santori, S. McPhail, F. Polonara, Thermochemical model and experimental validation of a tubular sofc cell comprised in a $1 \mathrm{kw}$ el stack designed for $\mu \mathrm{chp}$ applications, International Journal of Hydrogen Energy 39 (36) (2014) 21714-21723.

[26] F. Cappa, A. L. Facci, S. Ubertini, Proton exchange membrane fuel cell for cooperating households: A convenient combined heat and power solution for residential applications, Energy 90 (2015) 1229-1238.

[27] G. Bizzarri, G. L. Morini, Greenhouse gas reduction and primary energy savings via adoption of a fuel cell hybrid plant in a hospital, Applied Thermal Engineering 24 (2-3) (2004) $383-400$.

[28] A. Mehmeti, F. Santoni, M. Della Pietra, S. J. McPhail, Life cycle assessment of molten carbonate fuel cells: State of the art and strategies for the future, Journal of Power Sources 308 (2016) 97-108.

[29] Power grid balancing of energy systems with high renewable energy penetration by demand response, Utilities Policy 16 (2) (2008) $90-98$

[30] Y. Shiohara, T. Tsuji, T. Oyama, T. Shinji, M. Tadokoro, A study on cooperative voltage and frequency control method using distributed generations considering large penetration of renewable energy sources, Electrical Engineering in Japan 197 (2) (2016) 3-12.

[31] M. Andrychowicz, B. Olek, J. Przybylski, Review of the methods for evaluation of renewable energy sources penetration and ramping used in the scenario outlook and adequacy forecast 2015. case study for poland, Renewable and Sustainable Energy Reviews 74 (2017) 703 - 714.

[32] G. J. May, A. Davidson, B. Monahov, Lead batteries for utility energy storage: A review, Journal of Energy Storage 15 (2018) 145 - 157.

[33] R. Doering, B. Lin, Optimum operation of a total energy plant, Computers and Operations Research 6 (1) (1979) 33-38.

[34] L. Andreassi, M. Ciminelli, M. Feola, S. Ubertini, Innovative method for energy management: Modelling and optimal operation of energy systems, Energy and Buildings 41 (4) (2009) 436-444.

[35] A. L. Facci, L. Andreassi, S. Ubertini, Optimization of chcp (combined heat power and cooling) systems operation strategy using dynamic programming, Energy 66 (2014) 387-400.

[36] Y. Lu, S. Wang, K. Shan, Design optimization and optimal control of grid-connected and standalone nearly/net zero energy buildings, Applied Energy 155 (Supplement C) (2015) 463 - 477.

[37] M. Saffari, A. de Gracia, C. Fern $\tilde{A}_{i}{ }_{n d e z}$, M. Belusko, D. Boer, L. F. Cabeza, Optimized demand side management $(\mathrm{dsm})$ of peak electricity 
demand by coupling low temperature thermal energy storage (tes) and solar pv, Applied Energy 211 (2018) $604-616$.

[38] A. M. Kler, E. L. Stepanova, A. S. Maximov, The optimization problems of cp operation, Journal of Physics: Conference Series 891 (1) (2017) 012215 .

[39] E. Cardona, A. Piacentino, F. Cardona, Matching economical, energetic and environmental benefits: An analysis for hybrid chcp-heat pump systems, Energy Conversion and Management 47 (20) (2006) 3530 - 3542, heat Transfer in Components and Systems for Sustainable Energy Technologies: Heat-SET 2005, 5-7 April 2005, Grenoble, France.

[40] A. Hawkes, M. Leach, Cost-effective operating strategy for residential micro-combined heat and power, Energy 32 (5) (2007) $711-723$.

[41] E. Fabrizio, M. Filippi, J. Virgone, An hourly modelling framework for the assessment of energy sources exploitation and energy converters selection and sizing in buildings, Energy and Buildings 41 (10) (2009) 1037-1050.

[42] B. Cai, H. Li, Y. Hu, G. Zhang, Operation strategy and suitability analysis of chp system with heat recovery, Energy and Buildings 141 (2017) 284 $-294$.

[43] A. Piacentino, F. Cardona, On thermoeconomics of energy systems at variable load conditions: Integrated optimization of plant design and operation, Energy Conversion and Management 48 (8) (2007) 2341 - 2355.

[44] A. N. Ünal, S. Ercan, G. Kayakutlu, Optimisation studies on trigeneration: a review, International Journal of Energy Research 39 (10) (2015) 1311-1334.

[45] A. L. Facci, L. Andreassi, F. Martini, S. Ubertini, Comparing energy and cost optimization in distributed energy systems management, Journal of Energy Resources Technology 136 (3) (2014) 032001.

[46] A. Collazos, F. Maréchal, C. G Predictive optimal management method for the control of polygeneration systems, Computers \& Chemical Engineering 33 (10) (2009) 1584 - 1592, selected Papers from the 18th European Symposium on Computer Aided Process Engineering (ESCAPE18).

[47] H. B. Puttgen, P. R. MacGregor, Optimum scheduling procedure for cogenerating small power producing facilities, Power Systems, IEEE Transactions on 4 (3) (1989) 957-964.

[48] M. v. Spakovsky, V. Curti, M. Batato, The performance optimization of a gas turbine cogeneration/heat pump facility with thermal storage, Journal of engineering for gas turbines and power 117 (1).

[49] C. Frangopoulos, A. Lygeros, C. Markou, P. Kaloritis, Thermoeconomic operation optimization of the hellenic aspropyrgos refinery combinedcycle cogeneration system, Applied Thermal Engineering 16 (12) (1996) 949-958.

[50] S. Mitra, L. Sun, I. E. Grossmann, Optimal scheduling of industrial combined heat and power plants under time-sensitive electricity prices, Energy 54 (0) (2013) $194-211$.

[51] X. Kong, R. Wang, X. Huang, Energy optimization model for a CCHP system with available gas turbines, Applied Thermal Engineering 25 (2005) 377-391.

[52] X. Kong, R. Wang, Y. Li, X. Huang, Optimal operation of a microcombined cooling, heating and power system driven by a gas engine, Energy Conversion and Management 50 (3) (2009) 530-538.

[53] D. Chiappini, A. L. Facci, L. Tribioli, S. Ubertini, SOFC management in distributed energy systems, Journal of Fuel Cell Science and Technology 8 (3).

[54] K. Mařík, Z. Schindler, P. Stluka, Decision support tools for advanced energy management, Energy 33 (6) (2008) 858-873.

[55] S. Sivasubramani, K. Swarup, Hybrid SOA-SQP algorithm for dynamic economic dispatch with valve-point effects, Energy 35 (12) (2010) 50315036.

[56] T. Niknam, H. D. Mojarrad, M. Nayeripour, A new fuzzy adaptive particle swarm optimization for non-smooth economic dispatch, Energy 35 (4) (2010) 1764-1778.

[57] M. de Athayde Costa e Silva, C. E. Klein, V. C. Mariani, L. dos Santos Coelho, Multiobjective scatter search approach with new combination scheme applied to solve environmental/economic dispatch problem, Energy 53 (0) (2013) 14-21.

[58] H. Doagou-Mojarrad, G. Gharehpetian, H. Rastegar, J. Olamaei, Optimal placement and sizing of DG (distributed generation) units in distribution networks by novel hybrid evolutionary algorithm, Energy 54 (0) (2013) $129-138$.
[59] A. Fumarola, L. Tribioli, F. Martini, Methodology procedure for hybrid electric vehicles design, in: Proceedings of International Conference on Engines and Vehicles, SAE Conference, 2011.

[60] A. L. Facci, F. Martini, S. Pirozzi, A. Zanfardino, S. Ubertini, Control strategy optimization of hvac plants, in: AIP Conference Proceedings, Vol. 1648, AIP Publishing, 2015, p. 570004.

[61] M. Schicktanz, J. Wapler, H.-M. Henning, Primary energy and economic analysis of combined heating, cooling and power systems, Energy 36 (1) (2011) 575-585.

[62] S. Dasgupta, C. H. Papadimitriou, U. V. Vazirani, Algorithms, McGrow Hill, 2006.

[63] J. W. Chinneck, Practical optimization: a gentle introduction, Systems and Computer Engineering, Carleton University. Available at: http://www. sce. carleton. ca/faculty/chinneck/po. html.

[64] cOMPunity, OpenMP, Enabling HPC since 1997 (2016). URL http: / / www . openmp. org/

[65] A. L. Facci, G. Loreti, S. Ubertini, F. Barbir, T. Chalkidis, R.-P. Eßling, T. Peters, E. Skoufa, R. Bove, Numerical assessment of an automotive derivative CHPfuel cell system, in: Proceedings of the 8'th International Conference on Applied Energy, Elsevier, 2016.

[66] Aspen, Aspenplus (2016).

URL http://www. aspentech.com/products/engineering /aspen-plus/

[67] GME, historical data day ahead market (2016)

URL http: //www.mercatoelettrico.org/En/download/ Datistorici.aspx

[68] Indicazioni metodologiche per l'applicazione dei fattori di co nversi o ne al metodo di calcolo di cui alla dgr 967/2015 e alla dgr $1275 / 2015$, Tech. rep., Regione Emilia Romagna (2015).

[69] ENEA, Poteri calorifici inferiori dei combustibili e fattori di emissione della CO2 (2016).

URL http: / / www.efficienzaenergetica.enea.it/regioni1016 /siape/poteri-calorifici-inferiori-dei-combustibili1017 -e-fattori-di-emissione-della-co2

[70] Eurostat, Eurostat, your key to european statistics (2016). URL http: / / ec. europa. eu/eurostat/web/energy/data/ database

[71] AEEG, Condizioni economiche per i clienti del mercato tutelato. URL http: / / www .autorita.energia.it/it/dati/condec.htons

[72] Office of Energy Efficiency and Renewable Energy, Commercial ref- 1024 erence buildings, http://energy.gov/eere/buildings/commercial-reference- 1025 buildings (November 2016).

[73] M. J. Laustsen, Energy efficiency requirements in building codes, energy efficiency policies for new buildings (2008).

[74] Micro-CHP, PEM fuel cells. URL http: / / www.microchap.info/pem fuel_cells.htm

[75] I. Staffell, R. Green, The cost of domestic fuel cell micro-chp systems, International Journal of hydrogen energy 38 (2) (2013) 1088-1102.

[76] Elcore 2400 Max - das Komplettpaket. URL http: / /www.elcore.com/elcore-energiesysteme/ elcore-2400-max/

[77] Ballard, Economics of Fuel Cell Solutions for Backup Power. URL http: / / ballard.com/files/PDF/Backup_Power/ BUP_EmrgncyEcon_EGen_091712-01.pdf

[78] Fuel cell boiler Vitovalor 300-P.

URL http: //www.viessmann.co.uk/en/residential -buildings/combined-heat-and-power-generation/ micro-chp-unit-based-on-a-fuel-cell/vitovalor$300 \mathrm{p} \cdot \mathrm{html}$

[79] Fuel cells and hydrogen joint undertaking (FCH JU) multi-annual work plan 2014-2020.

URL http: //www. fch.europa.eu/sites/default/files/ $\mathrm{FCH} 2 \div 20 \mathrm{JU} \div 20-\div 20 \mathrm{Multi} \div 20 \mathrm{Annual} \div 20$ Work $\div 20 \mathrm{Plan} \div 20$ $-\div 20 M A W P \div 20 \% 28 I D \div 20623483 \div 29 . p d f$

[80] J. Spendelow, J. Marcinkoski, D. Papageorgopoulos, Micro CHP fuel cell system targets (2012).

URL https: / / www. hydrogen. energy.gov/pdfs / 11016_micro_chp_target.pdf 